\title{
Navigating the Updated Anaphylaxis Parameters
}

\author{
Stephen F. Kemp, MD
}

\begin{abstract}
Anaphylaxis, an acute and potentially lethal multi-system clinical syndrome resulting from the sudden, systemic degranulation of mast cells and basophils, occurs in a variety of clinical scenarios and is almost unavoidable in medical practice. Healthcare professionals must be able to recognize its features, treat an episode promptly and appropriately, and be able to provide recommendations to prevent future episodes. Epinephrine, administered immediately, is the drug of choice for acute anaphylaxis. The discussion provides an overview of one set of evidence-based and consensus parameters for the diagnosis and management of anaphylaxis.
\end{abstract}

Key words: anaphylaxis, epinephrine, management, prevention

W ith the clear objective of improving the quality of patient care through the provision of evidencebased and consensus guidelines for anaphylaxis, "The Diagnosis and Management of Anaphylaxis: An Updated Practice Parameter" was developed by the Joint Task Force on Practice Parameters, ${ }^{1}$ which represents the American Academy of Allergy, Asthma and Immunology (AAAAI); the American College of Allergy, Asthma and Immunology (ACAAI); and the Joint Council of Allergy, Asthma and Immunology. This document updates and expands on its 1998 predecessor. $^{2}$ Because this effort involved many contributors, no single individual, including those who served on the Joint Task Force, is authorized to provide an official AAAAI or ACAAI interpretation of these practice parameters. The diagnosis and management of anaphylactic reactions must be individualized on the basis of unique features in particular patients.

Stephen F. Kemp: Division of Clinical Immunology and Allergy, Department of Medicine, The University of Mississippi Medical Center, Jackson, MS.

Dr. Kemp is a consultant to Verus Pharmaceuticals (San Diego, CA) and has participated in the Speaker's Bureau of Dey Laboratories (Napa, CA), both regarding anaphylaxis.

A portion of this narrative was presented in a satellite symposium at the 2005 Annual Meeting of the Canadian Society of Allergy and Clinical Immunology, Winnipeg, MB, September 24, 2005. Some of the material has been updated.

Correspondence to: Dr. Stephen F. Kemp, Division of Clinical Immunology and Allergy, Department of Medicine, The University of Mississippi Medical Center, Jackson, MS; e-mail: skemp@medicine. umsmed.edu.

DOI 10.2310/7480.2007.00002
In keeping with this spirit, the following discussion focuses on material deemed to be substantively updated or changed from the 1998 parameters. Any discussion that may depart from consensus or reflect personal opinion is clearly designated.

\section{Background}

Anaphylaxis is not a reportable disease, and both its morbidity and mortality are probably underestimated. A variety of statistics on the epidemiology of anaphylaxis have been published, but the lifetime risk per person in the United States and Canada is presumed to be 1 to $3 \%$, with a mortality rate of $1 \%{ }^{3-7}$

There is no universally accepted definition of anaphylaxis. Three proposed consensus definitions are presented. The World Allergy Organization, composed of 39 countries, proposed that older, traditional terminology, anaphylactic and anaphylactoid, be discarded in favour of immunologic and nonimmunologic anaphylaxis. ${ }^{8}$ The Joint Task Force on Practice Parameters states, "Anaphylaxis is an acute lifethreatening reaction that results from the sudden systemic release of mast cells and basophil mediators. It has varied clinical presentations, but respiratory compromise and cardiovascular collapse cause the most concern because they are the most frequent causes of anaphylactic fatalities." More recently, the US National Institute of Allergy and Infectious Disease and the Food Allergy and Anaphylaxis Network (Chantilly, VA) convened two symposia, during which an international and interdisciplinary group of representatives and experts from 13 professional, government, and lay organizations attempted, among other tasks, to establish clinical criteria that would increase diagnostic precision in anaphylaxis. ${ }^{9,10}$ The working definition pro- 
posed is the following: "Anaphylaxis is a serious allergic reaction that is rapid in onset and may cause death." Anaphylaxis was considered to be highly likely if any one of the following was present: (1) acute onset (minutes to hours) with involvement of skin, mucosa, or both and at least one of the following: respiratory compromise, hypotension, or endorgan dysfunction; (2) two or more of the following that occur rapidly after exposure to a likely allergen for that patient (minutes to hours): involvement of skin or mucosa, respiratory compromise, hypotension or associated symptoms, persistent gastrointestinal symptoms; (3) hypotension after exposure to a known allergen for that patient (minutes to hours): age-specific low systolic blood pressure or greater than $30 \%$ decline from that individual's baseline.

Symposium participants believed that the presence of any one of the three criteria likely would identify anaphylaxis accurately in more than $95 \%$ of circumstances, but they agreed that validation by prospective multicentre clinical survey is necessary. ${ }^{10}$

\section{Clinical Manifestations of Anaphylaxis}

In addition to the criteria included in the working definition, anaphylaxis might affect mentation (hypoxemia might cause acute impairment), and some patients might experience rhinitis, headache, uterine cramps, or a feeling of impending doom. Urticaria and angioedema are the most common manifestations (more than $90 \%$ in retrospective series) ${ }^{11-14}$ but might be delayed or absent in rapidly progressive anaphylaxis. Urticaria and angioedema might be part of the continuum of anaphylaxis but do not constitute anaphylaxis if they are present in the absence of other physical signs and symptoms suggestive of the diagnosis. ${ }^{1}$

Respiratory symptoms are the next most common manifestations, followed by dizziness, unconsciousness, and gastrointestinal symptoms. The more rapidly anaphylaxis occurs after exposure to an offending stimulus, the more likely the reaction is to be severe and potentially life-threatening. ${ }^{15,16}$ Anaphylaxis often produces signs and symptoms within 5 to 30 minutes, but reactions sometimes may not develop for several hours. The response to anaphylaxis by a patient's intrinsic compensatory mechanisms (ie, endogenous catecholamines, angiotensin) also influences the extent of clinical manifestations and, when adequate, may be lifesaving independent of medical intervention.

\section{Recurrent Anaphylaxis}

Depending on the report, recurrent (biphasic) anaphylaxis occurs in up to $20 \%$ of patients who experience anaphylaxis. ${ }^{11,17-22}$ Signs and symptoms experienced during the recurrent phase of anaphylaxis may be equivalent to or worse than those observed in the initial reaction and may occur up to 38 hours after apparent remission. ${ }^{22}$ Thus, it may be necessary to monitor patients 24 hours or more after apparent recovery from the initial phase. The updated parameters recommend that observation periods should be individualized and based on such factors as comorbid conditions and distance from the patient's home to the closest emergency facility, particularly since there are no reliable predictors of recurrent anaphylaxis on the basis of initial clinical presentation. ${ }^{1}$

\section{Diagnosis of Anaphylaxis}

Anaphylaxis remains a clinical diagnosis based on probability and pattern recognition. No evaluation can conclusively prove causation of anaphylaxis without directly challenging the patient with the suspected agent, which is generally contraindicated owing to ethical and safety concerns. Cause and effect may often be demonstrated historically in patients who experience objective findings of anaphylaxis after inadvertent re-exposure to the offending agent. Virtually any agent capable of activating mast cells or basophils may potentially precipitate anaphylaxis. The most common identifiable causes of anaphylaxis are foods, medications, insect stings, and immunotherapy injections. ${ }^{4,23-25}$ Anaphylaxis to peanuts and/or tree nuts causes the greatest concern because of its life-threatening severity, especially in patients with asthma, and the tendency for patients to develop lifelong allergic responsiveness to these foods.

Idiopathic anaphylaxis, anaphylaxis with no identifiable cause, has accounted for about one-third of cases in most retrospective studies of anaphylaxis. ${ }^{4,11,23}$ However, of 601 patients evaluated over two decades in a universityaffiliated practice (the largest retrospective series), 356 subjects (59\%) were deemed to have idiopathic anaphylaxis. ${ }^{14}$ Idiopathic anaphylaxis remains a diagnosis of exclusion, however. Serial histories and diagnostic tests for foods, spices, and vegetable gums occasionally identify a specific culprit in patients previously presumed to have idiopathic anaphylaxis. ${ }^{24}$

\section{Differential Diagnosis}

Several systemic disorders share clinical features with anaphylaxis. The vasodepressor (vasovagal) reaction probably is the condition most commonly confused with anaphylactic reactions. In vasodepressor reactions, however, 
urticaria are absent, dyspnea is generally absent, the blood pressure is usually normal or elevated, and the skin is typically cool and pale. Tachycardia is the rule in anaphylaxis. Bradycardia may be under-recognized in anaphylaxis, however. Brown and colleagues conducted sting challenges in 19 patients known to be allergic to jack jumper ants (Myrmecia) ${ }^{26}$ All eight patients who became hypotensive developed bradycardia after an initial tachycardia.

Several conditions can cause abrupt and dramatic patient collapse and potentially be confused with anaphylaxis. Among conditions to consider are systemic mast cell disorders, myocardial dysfunction, pulmonary embolism, foreign-body aspiration (especially in children), acute poisoning, hypoglycemia, and seizure disorder. Specific signs and symptoms of anaphylaxis can present singly in other disorders. Examples are urticaria-angioedema (in the absence of other signs and symptoms suggestive of anaphylaxis), hereditary angioedema, asthma, and acute anxiety (eg, hyperventilation syndrome or panic attack). Postprandial syndromes (eg, scombroidosis), "flushing syndromes" (eg, metastatic carcinoid), and psychiatric disorders that can mimic anaphylaxis can also contribute to diagnostic confusion. ${ }^{1}$

\section{Role of Diagnostic Testing}

Allergen-specific immunoglobulin E diagnostic skin testing may support a specific cause for anaphylaxis in some circumstances in which the patient has a compatible history (eg, venom or penicillin allergy). However, the immunochemistry of most drugs and biologic agents is not well defined, and reliable in vivo or in vitro testing is unavailable for most agents. ${ }^{27}$

Measurement of serum markers of mast cell activation and degranulation may be useful to confirm anaphylaxis in equivocal cases. Tryptase is the only protein that is concentrated selectively in the secretory granules of all human mast cells. Its plasma levels during mast cell degranulation correlate with the clinical severity of anaphylaxis. ${ }^{28}$ Since $\beta$-tryptase is stored in the secretory granules, its release may be more specific for mast cell activation than $\alpha$-protryptase, which is secreted constitutively. ${ }^{29}$ However, tryptase levels may not be elevated in all forms of anaphylaxis (eg, it is frequently normal in foodassociated anaphylaxis). ${ }^{18,30}$

Plasma histamine levels become elevated within 5 to 10 minutes after mast cell activation but return to baseline levels after 30 to 60 minutes. Histamine and tryptase elevations do not necessarily correlate. In an emergency department study, elevated histamine levels were observed in 42 of 97 patients, but only 20 also exhibited increased tryptase levels. ${ }^{30}$ Histamine levels correlate with the severity and persistence of cardiopulmonary manifestations but do not correlate with the development of urticaria during anaphylaxis. ${ }^{30,31}$ Gastrointestinal signs and symptoms in anaphylaxis also have a greater association with histamine than with tryptase elevations. ${ }^{30}$

The ratio of total tryptase (alpha + beta) to beta helps distinguish anaphylaxis from systemic mastocytosis. A ratio greater than 20:1 supports mastocytosis, whereas a ratio less than 10 supports anaphylaxis from another source. ${ }^{32}$

\section{Maintaining the Professional Edge through Anaphylaxis Preparedness}

A suggested protocol to deal with anaphylactic episodes is available for reference, and appropriate equipment is available to treat the episode. A sequential approach to management is outlined in Table 1 , and a sample treatment flowsheet is presented in Figure 1. It is important to stress that these steps are subject to physician discretion and that variations in sequence and performance rely on clinical judgment.

When a patient should be transferred to an emergency facility depends on the skill, experience, and clinical decision-making of the individual clinician. Ready access to telephone numbers for rescue squads or ambulance services may be helpful.

Both clinicians and office staff should maintain clinical proficiency in anaphylaxis management.

The emergency kit should be up-to-date and complete. Figure 2 provides a sample checklist to track the supplies needed to treat anaphylaxis and expiration dates for medications or fluids. Not all items need to be present in each office. Everyone directly involved in patient care should easily be able to locate necessary supplies, rapidly assemble fluids for intravenous administration, etc.

\section{Acute Management of Anaphylaxis}

In the management of anaphylaxis, judicious use of epinephrine and the maintenance of adequate oxygenation and effective circulatory volume are the most important considerations. Assessment and maintenance of airway, breathing, circulation, and mentation are essential, initial management steps. Altered mentation may reflect underlying hypoxia. Measurement of peak expiratory flow rate and pulse oximetry, where appropriate, may be useful to guide therapy. Patients are monitored continuously to facilitate prompt detection of any treatment complications. 
Table 1. Physician-Supervised Management of Anaphylaxis

I. Immediate intervention

a. Assessment of airway, breathing, circulation, and adequacy of mentation

b. Administer aqueous epinephrine $1: 1,000$ dilution, $0.2-0.5 \mathrm{~mL}(0.01 \mathrm{mg} / \mathrm{kg}$ in children; maximum dose $0.3 \mathrm{mg})$ intramuscularly every $5 \mathrm{~min}$, as necessary, to control symptoms and blood pressure.

II. Possibly appropriate, subsequent measures depending on response to epinephrine

a. Place patient in a recumbent position and elevate the lower extremities.

b. Establish and maintain an airway.

c. Administer oxygen.

d. Establish venous access.

e. Normal saline IV for fluid replacement.

III. Specific measures to consider after epinephrine injections, where appropriate

a. An epinephrine infusion might be prepared. Continuous hemodynamic monitoring is essential. (See Lieberman et al ${ }^{1}$ for specific details.)

b. Diphenhydramine. In the management of anaphylaxis, a combination of diphenhydramine and ranitidine is superior to diphenhydramine alone.

c. For bronchospasm resistant to epinephrine, use nebulized albuterol.

d. For refractory hypotension, consider dopamine, $400 \mathrm{mg}$ in $500 \mathrm{~mL} \mathrm{D} \mathrm{D}_{5} \mathrm{~W}$, administered intravenously at a rate of $2-20 \mu \mathrm{g} / \mathrm{kg} / \mathrm{min}$ titrated to maintain adequate blood pressure. Continuous hemodynamic monitoring is essential.

e. Where use of $\beta$-blockers complicates therapy, consider glucagon, 1-5 mg (20-30 $\mu \mathrm{g} / \mathrm{kg}$ [maximum $1 \mathrm{mg}$ in children]), administered intravenously over $5 \mathrm{~min}$ followed by an infusion, $5-15 \mu \mathrm{g} / \mathrm{min}$. Aspiration precautions should be observed.

f. For patients with a history of asthma and for those who experience severe or prolonged anaphylaxis, consider methylprednisolone $(1.0-2.0 \mathrm{mg} / \mathrm{kg} / \mathrm{d})$.

g. Consider transportation to the emergency department or an intensive care facility.

IV. Interventions for cardiopulmonary arrest occurring during anaphylaxis

High-dose epinephrine and prolonged resuscitation efforts are encouraged, if necessary, since efforts are more likely to be successful in anaphylaxis where the patient (often young) has a healthy cardiovascular system. (See Lieberman et al ${ }^{1}$ for specific details.)

VI. Observation and subsequent outpatient follow-up

Observation periods after apparent resolution must be individualized and based on such factors as the clinical scenario, comorbid conditions, and distance from the patient's home to the closest emergency department. After recovery from the acute episode, patients should receive epinephrine syringes and be instructed in proper technique. Everyone postanaphylaxis requires a careful diagnostic evaluation in consultation with an allergist-immunologist.

Adapted from Lieberman P et al. ${ }^{1}$

The recumbent position is strongly recommended. In a retrospective review of prehospital anaphylactic fatalities in the United Kingdom, the postural history was known for 10 individuals. ${ }^{33}$ Four of the 10 were associated with assumption of an upright or sitting posture and postmortem findings consistent with "empty heart" and pulseless electrical activity.

\section{Epinephrine}

Epinephrine is the treatment of choice for acute anaphylaxis. ${ }^{1,34-37}$ All subsequent therapeutic interventions depend on the initial response to epinephrine and the severity of the reaction. Development of toxicity or inadequate response to epinephrine injections indicates that additional therapeutic modalities are necessary. There is no absolute contraindication to epinephrine administration in anaphylaxis. ${ }^{1,38,39}$
The $\alpha$-adrenergic effect of epinephrine reverses peripheral vasodilation, which alleviates hypotension and also reduces angioedema and urticaria. It may also minimize further absorption of antigen from a sting or injection. The $\beta$-adrenergic properties of epinephrine increase myocardial output and contractility, cause bronchodilation, and suppress further mediator release from mast cells and basophils. ${ }^{40}$

Fatalities during witnessed anaphylaxis usually result from delayed administration of epinephrine and from severe respiratory and/or cardiovascular complications. In a retrospective review of six fatal and seven nonfatal episodes of food-induced anaphylaxis in children and adolescents, all patients who survived had received epinephrine before or within 5 minutes of developing severe respiratory symptoms. None of the patients with fatal attacks had received epinephrine prior to the onset of severe respiratory 
Name

Date of Birth

Prior systemic rxn:

Date/time of rxn:

History of the systemic reaction (SR):

Immediate measures:

_ Assess airway, breathing, circulation, and orientation

_Injectable epinephrine

_Activate EMS (call 911 or local rescue squad) $\mathrm{Y} / \mathrm{N}$ Time called:

_Management algorithm reviewed (as needed)

Signs and Symptoms (Circle pertinent findings):

$\begin{array}{ll}\text { Respiratory } & \text { Skin } \\ \text { Dyspnea, chest tightness } & \text { Urticaria } \\ \text { Wheezing } & \text { Angioedema } \\ \text { Cough } & \text { Generalized itch } \\ \text { Stridor } & \text { Flushing }\end{array}$

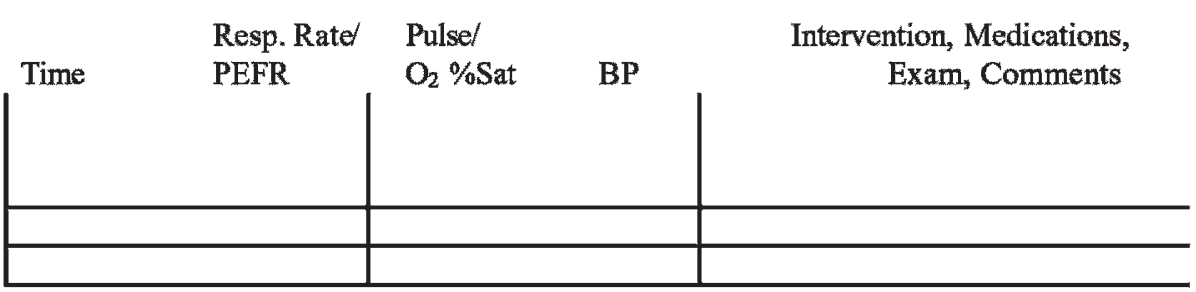

Eye/Nasal Vascular Other

Runny nose Hypotension Difficulty swallowing

Red eyes Chest discomfort Abdominal pain, nausea, emesis, diarrhea

Congestion Dizziness, syncope Diaphoresis

Sneezing Headache Apprehension

Time $(\mathrm{am} / \mathrm{p} \mathrm{m}) /$ Condition upon release:

Patient instructions:

Follow-up call to patient: Time

Clinical impression:

Signatures

True SR Comments:

Figure 1. Anaphylaxis treatment record. Adapted with permission from Lieberman $\mathrm{P}$ et al. ${ }^{1}$

symptoms. ${ }^{18}$ Analysis of data from a national case registry of fatal food anaphylaxis in the United States indicates that few individuals (3 of 32) had epinephrine syringes available at the time of fatal reaction. ${ }^{41}$ Similarly, Pumphrey determined that epinephrine was administered in $62 \%$ of the fatal anaphylactic reactions that he reviewed, only $14 \%$ prior to cardiac arrest. ${ }^{42}$

Aqueous epinephrine 1:1,000 dilution, 0.2 to $0.5 \mathrm{~mL}$ $(0.01 \mathrm{mg} / \mathrm{kg}$ in children; maximum dose $0.3 \mathrm{mg})$ administered intramuscularly or subcutaneously every 5 minutes, as necessary, should be used to control symptoms and sustain or increase blood pressure. The 5-minute interval between injections can be liberalized, if the clinician deems it appropriate, to permit more frequent injections. ${ }^{1}$

Comparisons of intramuscular injections with subcutaneous injections have not been done during acute anaphylaxis. However, absorption is complete and more rapid (mean maximum plasma epinephrine concentration of $2,136 \pm 351 \mathrm{pg} / \mathrm{mL}$ at a mean time of $8 \pm 2$ minutes) in asymptomatic children who receive epinephrine intramus- cularly in the thigh with an autoinjector. ${ }^{43}$ Intramuscular injection into the thigh (vastus lateralis) in asymptomatic adults is also superior to intramuscular or subcutaneous injection into the arm (deltoid). ${ }^{44}$ Spring-loaded, automatic epinephrine syringes administered intramuscularly and intramuscular epinephrine injections through a tuberculin syringe into the thigh in adults and children not experiencing anaphylaxis provide dose-equivalent plasma levels. ${ }^{43,44}$ Similar studies comparing intramuscular injections with subcutaneous injections in the thigh have not yet been done, however.

The UK consensus panel on emergency guidelines and the international consensus guidelines for emergency cardiovascular care both recommend intramuscular epinephrine injections for anaphylaxis. ${ }^{35-37}$ These guidelines also propose that epinephrine can be repeated every 5 minutes, as clinically needed, in both adults and children, ${ }^{35,36}$ although the updated cardiovascular care guidelines (published after the updated anaphylaxis parameter) have modified the recommended frequency 
Flowsheet Treatment Algorithm

BP cuff/monitor* Stethoscope

\section{AIRWAY}

_Disposable face mask
_ Infant
_Toddler
_Child/small adult
Adult
Nasal cannula (adult)
Oropharyngeal airways
$-6 \mathrm{~cm}$
$-7 \mathrm{~cm}$
$-8 \mathrm{~cm}$
$-9 \mathrm{~cm}$
$-10 \mathrm{~cm}$

\section{MEDICATIONS}

Epinephrine 1:1,000 $1 \mathrm{~mL}$ ampules (3)

Epinephrine 1:1,000 multidose vial

Diphenhydramine (Benadryl) $50 \mathrm{mg} / \mathrm{mL}$ IV

Benadryl liquid $12.5 \mathrm{mg} / 5 \mathrm{~mL}$

Ranitidine (Zantac) $25 \mathrm{mg} / \mathrm{mL}$ IV

Prednisone $10 \mathrm{mg}$ tablets

Prednisolone syrup $15 \mathrm{mg} / \mathrm{mL}$

Methylprednisolone (Solu-Medrol) $125 \mathrm{mg}$ vial

Glucagon $1 \mathrm{mg} / \mathrm{mL}$ vial

Atropine $0.5 \mathrm{mg} / \mathrm{mL}$ IV

Albuterol inhalation solution, $0.5 \%$

Dopamine $200 \mathrm{mg} / 5 \mathrm{~mL}$ ( 2 ampules)

\section{OXYGEN}

\author{
$\mathrm{O}_{2}$ E-cylinder w/wrench; $>1,100$ psi ( $>$ half-full) \\ Extension tubing \\ _Adult pocket mask with extension port \\ Pediatric oxygen mask \\ Pediatric Ambubag
}

\section{SUPPLIES}

$0.9 \%$ normal saline (4 $1,000 \mathrm{~mL}$ bags)

$5 \%$ dextrose (1 $250 \mathrm{~mL}$ bag for admixture)

Macrodrip admin. sets, $10-15$ drops $/ \mathrm{mL}$

Minidrip set, 60 drops/mL (for dopamine)

Connection tubing

Three-way stopcock

Catheter needles, gauge $16,18,20,22$

Butterfly needles, gauge 19,21

Syringes w/needles $1,10,20 \mathrm{~mL}$

Tourniquet (2) - may substitute extra BP cuff

1" synthetic tape (eg, Transpore)

Latex-free gloves

Alcohol swabs (box)

IV Pole

*Sphygmomanometer/electronic BP monitoring device should be calibrated annually. A minimum of 3 cuff sizes should be available (child, adult, obese/large adult).

Replace supplies within one month of expiration date. Check supplies monthly and re-stock after use. Sphygmomanometer and oxygen tank connections should be checked weekly for air leak or malfunction.

Note: Not all items need to be present in each treatment setting.

Initials:

Date:

Figure 2. Suggested anaphylaxis supply checksheet. Adapted with permission from Lieberman $\mathrm{P}$ et al. ${ }^{1} \mathrm{BP}=$ blood pressure; IV $=$ intravenous.

of intramuscular injections to every 15 to 20 minutes, as needed. $^{37}$ The guidelines provide no explanation or reference on which this change is based.

No established dosage or regimen for intravenous epinephrine in anaphylaxis is recognized (see the updated parameter $^{1}$ for sample infusion protocols). Because of the risk of potentially lethal arrhythmias, epinephrine should be administered intravenously only during cardiac arrest or to profoundly hypotensive patients who have failed to respond to intravenous volume replacement and multiple epinephrine injections in the thigh. Continuous hemodynamic monitoring is essential where it is available (eg, emergency department or intensive care facility). ${ }^{45}$ However, the updated anaphylaxis parameter states that intravenous administration of epinephrine should not be precluded in a special circumstance in which the clinician deems its administration is essential after failure of several epinephrine injections and no such monitoring is available. Under such an extreme scenario, monitoring by available means (eg, electrocardiographic monitoring and every-minute pulse and blood pressure measurements) should be conducted. ${ }^{1}$

\section{Oxygen and Airway Adjuncts}

Oxygen should be administered to patients with anaphylaxis who have pre-existing hypoxemia or myocardial dysfunction, have prolonged reactions, require multiple 
doses of epinephrine, or receive inhaled $\beta_{2}$ agonists. Continuous pulse oximetry or arterial blood gas determination (where available) should guide oxygen therapy if development of hypoxemia is a concern.

Given that adequate oxygenation also depends on ventilation, it may be necessary to establish and maintain an airway and/or provide ventilatory assistance. One of the easiest, quickest, and most effective ways to support ventilation involves a one-way valve face mask with oxygen inlet port (eg, Pocket-Mask [Laerdal Medical Corporation, Gatesville, TX] or similar device). Oxygen saturations comparable to endotracheal intubation have been demonstrated in patients who require artificial ventilation by mouth-to-mask technique with oxygen attached to the inlet port. Patients with adequate, spontaneous respirations may breathe through the mask.

Ambubags of less than $700 \mathrm{~mL}$ are discouraged in adults in the absence of an endotracheal tube since ventilated volume will not overcome the 150 to $200 \mathrm{~mL}$ of anatomic dead space to provide effective tidal volume. Recommended tidal volume during artificial ventilation is 6 to $7 \mathrm{~mL} / \mathrm{kg}$ over 1.5 to 2 seconds. (Ambubags may be used in children provided that the reservoir volume of the device is sufficient. Avoid overinflation.) Endotracheal intubation or cricothyroidotomy may be considered where appropriate and provided that clinicians are adequately trained and proficient in this procedure.

The rate of administered oxygen depends on the device used and clinical response. A nasal cannula will deliver an oxygen concentration of 25 to $40 \%$ with a 4 to $6 \mathrm{~L} / \mathrm{min}$ flow. A simple plastic face mask will deliver an oxygen concentration of 50 to $60 \%$ with an 8 to $12 \mathrm{~L} / \mathrm{min}$ flow. By comparison, the one-way valve face mask with oxygen inlet valve permits ventilation with up to $50 \%$ oxygen at a flow rate of $10 \mathrm{~L} / \mathrm{min}$ and approaching 90 to $100 \%$ if the opening of the mask is periodically occluded by the rescuer's tongue during mouth-to-mask ventilation.

\section{Persistent Hypotension: Appropriate Roles of Volume Replacement and Vasopressors}

\section{Special Considerations for $\boldsymbol{\beta}$-Adrenergic Antagonists}

Patients taking $\beta$-adrenergic antagonists may be more likely to experience severe anaphylactic reactions characterized by paradoxical bradycardia, profound hypotension, and severe bronchospasm. Use of selective $\beta_{1^{-}}$ antagonists does not reduce the risk of anaphylaxis since both $\beta_{1}$ and $\beta_{2}$ antagonists may inhibit the $\beta$-adrenergic receptor. ${ }^{46-48}$
Epinephrine administered during anaphylaxis to patients taking $\beta$-adrenergic antagonists may be ineffective. In this situation, both glucagon administration and isotonic volume expansion (multiple liters, in some circumstances) may be necessary. Glucagon bypasses the $\beta$-adrenergic receptor and may reverse refractory bronchospasm and hypotension during anaphylaxis in patients on $\beta$-adrenergic antagonists by activating adenyl cyclase directly. ${ }^{49-51}$ The recommended dosage for glucagon is 1 to $5 \mathrm{mg}(20-30 \mu \mathrm{g} / \mathrm{kg}$ [maximum $1 \mathrm{mg}$ ] in children) administered intravenously over 5 minutes and followed by an infusion, 5 to $15 \mu \mathrm{g} / \mathrm{min}$, titrated to clinical response. Protection of the airway against aspiration is important in severely drowsy or obtunded patients since glucagon may cause emesis. Placement in the lateral recumbent position may be sufficient for many of these patients.

\section{Fluid Resuscitation}

The patient whose hypotension persists despite epinephrine injections should receive intravenous crystalloid solutions or colloid volume expanders. (See Table 2 for age-dependent criteria for hypotension, as defined by international consensus guidelines for pediatric advanced life support.) Increased vascular permeability in anaphylaxis may permit transfer of $50 \%$ of the intravascular fluid into the extravascular space within 10 minutes. ${ }^{52,53}$ Crystalloid volumes (eg, saline) of up to $7 \mathrm{~L}$ may be necessary. One to $2 \mathrm{~L}$ of normal saline should be administered to adults at a rate of 5 to $10 \mathrm{~mL} / \mathrm{kg}$ in the first 5 minutes. Normal saline is preferred since lactated Ringer's may potentially contribute to metabolic acidosis and dextrose is rapidly extravasated from the intravascular circulation to the interstitial tissues. Large volumes are often required, but it may be appropriate to monitor patients with underlying congestive heart failure or chronic renal disease for signs of volume overload once the effective fluid deficit is replaced. Children should receive up to $30 \mathrm{~mL} / \mathrm{kg}$ in the first hour. Adults receiving colloid solution should receive $500 \mathrm{~mL}$ rapidly, followed by slow infusion. ${ }^{24}$

For intravenous volume replacement, one generally should insert the largest catheter needle possible into the largest secure peripheral vein available and use an administration set that permits rapid infusion of fluids. For example, large-bore cannula needles (14-16 gauge) and standard infusion sets (10-15 drops/mL) are preferred in adults. Intraosseous vascular access may be established in infants and children if urgent access is needed and 
Table 2. Special Considerations for Anaphylaxis in Children

\begin{tabular}{|c|c|c|c|}
\hline$I$ & \multicolumn{2}{|c|}{ Age } & Systolic Blood Pressure ( $\mathrm{mm} \mathrm{Hg}$ ) \\
\hline When is it hypotension? & \multicolumn{2}{|c|}{$\begin{array}{l}\text { Term neonates }(0-28 \mathrm{~d}) \\
\text { Infants }(1-12 \mathrm{mo}) \\
\text { Children }(>1-10 \mathrm{yr}) \\
\text { Beyond } 10 \mathrm{yr}\end{array}$} & $\begin{aligned}<60 \\
<70 \\
<70+(2 \times \text { age in } y r) \\
<90\end{aligned}$ \\
\hline II & Medication & $\begin{array}{l}\text { Dose Range } \\
\text { ( } \mu g / k g / m i n)\end{array}$ & Preparation* \\
\hline \multirow[t]{2}{*}{$\begin{array}{l}\text { Infusion rates for epinephrine and } \\
\text { dopamine in children with cardiac arrest } \\
\text { or profound hypotension }\end{array}$} & Dopamine & $2-20$ & $\begin{array}{l}6 \times \text { body weight (in } \mathrm{kg} \text { ) }=n \text { of } \mathrm{mg} \text { diluted to } \\
\text { total } 100 \mathrm{~mL} \text { saline; then } 1 \mathrm{~mL} / \mathrm{h} \text { delivers } 1 \\
\mu \mathrm{g} / \mathrm{kg} / \mathrm{min}\end{array}$ \\
\hline & Epinephrine & 0.1 & $\begin{array}{l}0.6 \times \text { body weight (in } \mathrm{kg} \text { ) }=n \text { of } \mathrm{mg} \text { diluted } \\
\text { to total } 100 \mathrm{~mL} \text { saline; then } 1 \mathrm{~mL} / \text { h delivers } \\
0.1 \mu \mathrm{g} / \mathrm{kg} / \mathrm{min}\end{array}$ \\
\hline
\end{tabular}

Adapted with permission from Lieberman $\mathrm{P}$ et al. ${ }^{1}$

*Infusion rates shown use the "Rule of 6." An alternative is to prepare a more dilute or more concentrated drug solution based on a standard drug concentration, in which case an individual dose must be calculated for each patient and each infusion rate, as follows: infusion rate ( $\mathrm{mL} / \mathrm{h})=($ weight $[\mathrm{kg}] \times$ dose $[\mu \mathrm{g} / \mathrm{kg} / \mathrm{min}] \times 60 \mathrm{~min} / \mathrm{h}) /$ concentration $(\mu \mathrm{g} / \mathrm{mL})$.

reliable venous access cannot be achieved rapidly. The microdrop infusion set (60 drops $/ \mathrm{mL}$ ) is appropriate for keep-open intravenous lines and infusions of medications (eg, epinephrine or a vasopressor), but it does not permit rapid volume replacement.

\section{Vasopressors}

Vasopressors, such as dopamine $400 \mathrm{mg}$ in $500 \mathrm{~mL}$ of $5 \%$ dextrose) administered at 2 to $20 \mu \mathrm{g} / \mathrm{kg} / \mathrm{min}$ and titrated to maintain systolic blood pressure greater than $90 \mathrm{~mm} \mathrm{Hg}$, should be administered to increase cardiac output if epinephrine injections and volume expansion fail to alleviate hypotension. (See Table 2 for pediatric dosing of dopamine.) Dopamine increases the force and rate of myocardial contractions while maintaining or enhancing renal and mesenteric blood flow. In contrast, norepinephrine constricts renal arteries. Vasopressors would not be expected to work as well in those patients who have already experienced maximal vasoconstriction from their internal compensatory response to anaphylaxis. A critical care specialist may need to be consulted for any patient with intractable hypotension.

\section{Role of Antihistamines and Corticosteroids}

Antihistamines ( $\mathrm{H}_{1}$ and $\mathrm{H}_{2}$ antagonists) support the treatment of anaphylaxis. However, these agents act much more slowly than epinephrine and should never be administered alone as treatment for anaphylaxis. Thus, antihistamines should be considered second-line treatment. ${ }^{1}$ Several reports on the treatment of anaphylaxis have demonstrated that a combination of $\mathrm{H}_{1}$ and $\mathrm{H}_{2}$ antagonists is more effective than treatment with an $\mathrm{H}_{1}$ antagonist alone. ${ }^{24}$

Systemic corticosteroids have no role in the acute management of anaphylaxis since even intravenous administration of these agents may have no effect for 4 to 6 hours after administration. Although corticosteroids traditionally have been used in the management of anaphylaxis, their effect has never been evaluated in placebo-controlled trials. Corticosteroids administered during anaphylaxis might provide additional benefit for patients with asthma or other conditions recently treated with corticosteroids. ${ }^{1}$

\section{Prevention of Anaphylaxis}

Basic principles to reduce the incidence of anaphylaxis and prevent future anaphylactic episodes in high-risk individuals are outlined in Table 3. An allergist-immunologist can provide comprehensive professional advice on these matters.

All patients at high risk of recurrent anaphylaxis should carry epinephrine syringes and know how to administer them. An EpiPen (Dey Laboratories, Napa, CA) is a spring-loaded, pressure-activated syringe with a single 0.3 mg dose (1:1,000 dilution) of epinephrine. It is easy to use and will inject through clothing. An EpiPen Jr., which delivers $0.15 \mathrm{mg}$ (1:2,000 dilution) of epinephrine, is 
Table 3. Preventive Measures to Reduce the Risk of Anaphylaxis

General measures

Obtain a thorough history to diagnose life-threatening food or drug allergy

Identify cause of anaphylaxis and those individuals at risk of future attacks

Provide instruction on proper reading of food and medication labels, where appropriate

Avoidance of exposure to antigens and cross-reactive substances

Optimal management of asthma and coronary artery disease

Implement a waiting period of 20 to $30 \mathrm{~min}$ after injections of drugs or other biologic agents

Consider a waiting period of $2 \mathrm{~h}$ if a patient receives an oral medication in the office he/she has never previously taken

Specific measures for high-risk patients

Individuals at high risk of anaphylaxis should carry self-injectable syringes of epinephrine at all times and receive instruction in proper use with a placebo trainer

MedicAlert or similar warning bracelets or chains

Substitute other agents for $\beta$-adrenergic antagonists, angiotensin-converting enzyme inhibitors, tricyclic antidepressants, monoamine oxidase inhibitors, and certain tricyclic antidepressants whenever possible

Slow, supervised administration of agents suspected of causing anaphylaxis, orally if possible

Where appropriate, use specific preventive strategies, including pharmacologic prophylaxis, short-term challenge and desensitization, and long-term desensitization

appropriate for children weighing less than $30 \mathrm{~kg}$. The TwinJect (Verus Pharmaceuticals, San Diego, CA) is a prefilled, pen-sized, epinephrine autoinjector with two doses of either 0.3 or $0.15 \mathrm{mg}$.

\section{Key Points from the Updated Anaphylaxis Parameters}

- Anaphylaxis is part of a continuum. The potential for clinical progression should not be underestimated.

- Anaphylaxis should be recognized and treated promptly.

- Therapeutic interventions in anaphylaxis should anticipate and adapt to clinical changes.

- Epinephrine and oxygen are the most important therapeutic agents used in the treatment of anaphylaxis.

- Any health care facility should have an action plan for anaphylaxis and have sufficient, well-trained personnel to handle it should it occur.

- Each office practice should know its strengths and limitations in emergency management.

- Prevention has paramount importance since optimal anaphylaxis treatment still fails some patients.

\section{References}

1. Lieberman P, Kemp SF, Oppenheimer J, et al, chief editors. Joint Task Force on Practice Parameters. The diagnosis and management of anaphylaxis: an updated practice parameter. J Allergy Clin Immunol 2005;115:S483-523.
2. Joint Task Force on Practice Parameters. The diagnosis and management of anaphylaxis. J Allergy Clin Immunol 1998;101: S465-528.

3. Valentine M, Frank M, Friedland L, et al. Allergic emergencies. In: Drause RM, editor. Asthma and other allergic diseases. NIAID Task Force Report. Bethesda (MD): National Institutes of Health; 1979. p. 467-507.

4. Yocum MW, Butterfield JH, Klein JS, et al. Epidemiology of anaphylaxis in Olmsted County: a population-based study. J Allergy Clin Immunol 1999;104:452-6.

5. Neugat AI, Ghatak AT, Miller RL. Anaphylaxis in the United States: an investigation into its epidemiology. Arch Intern Med 2001;161:15-21.

6. Simons FE, Peterson S, Black CD. Epinephrine dispensing for the out-of-hospital treatment of anaphylaxis in infants and children: a population-based study. Ann Allergy Asthma Immunol 2001;86: 622-6.

7. Simons FE, Peterson S, Black CD. Epinephrine dispensing patterns for an out-of-hospital population: a novel approach to studying the epidemiology of anaphylaxis. J Allergy Clin Immunol 2002;110: 647-51.

8. Johansson SGO, Bieber T, Dahl R, et al. Revised nomenclature for allergy for global use: report of the Nomenclature Review Committee of the World Allergy Organization, October 2003. J Allergy Clin Immunol 2004;113:832-6.

9. Sampson HA, Muñoz-Furlong A, Bock SA, et al. Symposium on the definition and management of anaphylaxis: summary report. J Allergy Clin Immunol 2005;115:584-91.

10. Sampson HA, Muñoz-Furlong A, Campbell RL, et al. Second symposium on the definition and management of anaphylaxis: summary report-second National Institute of Allergy and Infectious Disease/Food Allergy and Anaphylaxis Network symposium. J Allergy Clin Immunol 2006;117:391-7.

11. Kemp SF, Lockey RF, Wolf BL, Lieberman P. Anaphylaxis: a review of 266 cases. Arch Intern Med 1995;155:1749-54.

12. Ditto AM, Harris KE, Krasnick J, et al. Idiopathic anaphylaxis: a series of 335 cases. Ann Allergy Asthma Immunol 1996;77:285-91. 
13. Shadick NA, Liang MH, Partridge AJ, et al. The natural history of exercise-induced anaphylaxis: survey results from a 10-year followup study. J Allergy Clin Immunol 1999;104:123-7.

14. Webb LM, Lieberman P. Anaphylaxis: a review of 601 cases. Ann Allergy Asthma Immunol 2006;97:39-43.

15. James LP Jr, Austen KF. Fatal and systemic anaphylaxis in man. N Engl J Med 1964;270:597-603.

16. Lockey RF, Benedict LM, Turkeltaub PC, Bukantz SC. Fatalities from immunotherapy (IT) and skin testing (ST). J Allergy Clin Immunol 1987;79:660-77.

17. Stark BJ, Sullivan TJ. Biphasic and protracted anaphylaxis. J Allergy Clin Immunol 1986;78:76-83.

18. Sampson HA, Mendelson L, Rosen JP. Fatal and near-fatal anaphylactic reactions to food in children and adolescents. $\mathrm{N}$ Engl J Med 1992;327:380-4.

19. Douglas DM, Sukenick E, Andrade WP, Brown JS. Biphasic systemic anaphylaxis: an inpatient and outpatient study. J Allergy Clin Immunol 1994;93:977-85.

20. Brazil E, MacNamara AF. Not so immediate hypersensitivity-the danger of biphasic allergic reactions. J Accid Emerg Med 1998;15: 252-3.

21. Ellis AK, Day JH. Diagnosis and management of anaphylaxis. CMAJ 2003;169:307-12.

22. Ellis AK, Day JH. Biphasic anaphylaxis: a prospective examination of 103 patients for the incidence and characteristics of biphasic reactivity [abstract]. J Allergy Clin Immunol 2004;113:S259.

23. Brown AFT, McKinnon D, Chu K. Emergency department anaphylaxis: a review of 142 patients in a single year. J Allergy Clin Immunol 2001;108:861-6.

24. Lieberman P. Anaphylaxis and anaphylactoid reactions. In: Adkinson NF Jr, Yunginger JW, Busse WW, et al, editors. Middleton's allergy: principles and practice, 6th ed. St. Louis: Mosby-Year Book; 2003. p. 1497-522.

25. Stewart GE, Lockey RF. Systemic reactions from allergen immunotherapy. J Allergy Clin Immunol 1992;90:567-78.

26. Brown SGA, Blackman KE, Stenlake V, Heddle RJ. Insect sting anaphylaxis: prospective evaluation of treatment with intravenous adrenaline and volume resuscitation. Emerg Med J 2004;21:14954 .

27. deShazo RD, Kemp SF. Allergic reactions to drugs and biologic agents. JAMA 1997;278:1895-906.

28. Schwartz LB, Bradford TR, Rouse C, et al. Development of a new, more sensitive immunoassay for human tryptase: use in systemic anaphylaxis. J Clin Immunol 1994;14:190-204.

29. Kanthawatana S, Carias K, Arnaout R, et al. The potential clinical utility of serum alpha-protryptase levels. J Allergy Clin Immunol 1999;103:1092-9.

30. Lin RY, Schwartz LB, Curry A, et al. Histamine and tryptase levels in patients with acute allergic reactions: an emergency departmentbased study. J Allergy Clin Immunol 2000;106:65-71.

31. Smith PL, Kagey-Sobotka A, Bleecker ER, et al. Physiologic manifestations of human anaphylaxis. J Clin Invest 1980;66:107280 .

32. Schwartz LB, Irani AM. Serum tryptase and the laboratory diagnosis of systemic mastocytosis. Hematol Oncol Clin North Am 2000;14:641-57.

33. Pumphrey RSH. Fatal posture in anaphylactic shock. J Allergy Clin Immunol 2003;112:451-2.
34. AAAI Board of Directors. The use of epinephrine in the treatment of anaphylaxis. J Allergy Clin Immunol 1994;94:666-8.

35. Project Team of the Resuscitation Council (UK). Emergency medical treatment of anaphylactic reactions. J Accid Emerg Med 1999;16:243-7.

36. Cummins RO, Hazinski MR, Baskett PJF, et al, editors. Guidelines 2000 for cardiopulmonary resuscitation and emergency cardiovascular care: an international consensus on science. American Heart Association in collaboration with the International Liaison Committee on Resuscitation (ILCOR). Part 8: advanced challenges in resuscitation. Section 3: special challenges in ECC. Anaphylaxis. Circulation 2000;102 Suppl I:I241-3.

37. American Heart Association in collaboration with International Liaison Committee on Resuscitation. 2005 American Heart Association guidelines for cardiopulmonary resuscitation and emergency cardiovascular care. Anaphylaxis. Circulation 2005;112 Suppl IV:IV143-5.

38. AAAAI Board of Directors. Anaphylaxis in schools and other childcare settings. J Allergy Clin Immunol 1998;102:173-6.

39. Cydulka R, Davison R, Grammer L, et al. The use of epinephrine in the treatment of older adult asthmatics. Ann Emerg Med 1988;17: $322-6$.

40. Barach EM, Nowak RM, Lee TG, Tomanovich MC. Epinephrine for treatment of anaphylactic shock. JAMA 1984;251:2118-22.

41. Bock SA, Muñoz-Furlong A, Sampson HA. Fatalities due to anaphylactic reactions to foods. J Allergy Clin Immunol 2001;107: 191-3.

42. Pumphrey RSH. Lessons for management of anaphylaxis from a study of fatal reactions. Clin Exp Allergy 2000;30:1144-50.

43. Simons FER, Roberts JR, Gu X, Simons KJ. Epinephrine absorption in children with a history of anaphylaxis. J Allergy Clin Immunol 1998;101:33-7.

44. Simons FER, Gu X, Simons KJ. Epinephrine absorption in adults: intramuscular versus subcutaneous injection. J Allergy Clin Immunol 2001;108:871-3.

45. Kemp SF, Lockey RF. Anaphylaxis: a review of causes and mechanisms. J Allergy Clin Immunol 2002;110:341-8.

46. Toogood JH. Beta-blocker therapy and the risk of anaphylaxis. CMAJ 1987;136:929-33.

47. Toogood JH. Risks of anaphylaxis in patients receiving betablocker drugs [editorial]. J Allergy Clin Immunol 1988;81:1-5.

48. Lang DM. Anaphylactoid and anaphylactic reactions: hazards of beta-blockers. Drug Saf 1995;12:299-304.

49. Pollack CV. Utility of glucagon in the emergency department. J Emerg Med 1993;11:195-205.

50. Sherman MS, Lazar EJ, Eichacker P. A bronchodilator action of glucagon. J Allergy Clin Immunol 1988;81:908-11.

51. Zaloga GP, Delacey W, Holmboe E, Chemow B. Glucagon reversal of hypertension in a case of anaphylactoid shock. Ann Intern Med 1986;105:65-6.

52. Fisher M. Clinical observations on the pathophysiology and implications for treatment. In: Vincent JL, editor. Update in intensive care and emergency medicine. New York: SpringerVerlag; 1989. p. 309-16.

53. Fisher MM. Clinical observations on the pathophysiology and treatment of anaphylactic cardiovascular collapse. Anaesth Intensive Care 1986;14:17-21. 